\title{
PERCEPÇÃO E REPRESENTAÇÃO DA VIOLÊNCIA: AS "PAISAGENS DO MEDO" NOS MAPAS MENTAIS DOS ESTUDANTES DO ENSINO MÉDIO NA ZONA NORTE DE MANAUS
}

\author{
Risaldo Lima Duarte \\ Mestrando do Programa de Pós-graduação em Geografia - UFAM \\ Universidade Federal do Amazonas \\ limaduarte75@gmail.com \\ Amélia Regina Batista Nogueira \\ Professora Doutora do Programa de Pós-graduação em Geografia - UFAM \\ Universidade Federal do Amazonas \\ ab.nogueira@uol.com.br
}

\begin{abstract}
RESUMO: Os argumentos apresentados neste resumo estão relacionados à pesquisa desenvolvida no âmbito da geografia humanista, fundamentada na fenomenologia e está sendo realizada dentro do Programa de Pós-Graduação em Geografia do Departamento de Geografia, nível Mestrado da Universidade Federal do Amazonas, na linha de Pesquisa: Espaço território e cultura na Amazônia, sob a orientação da Dra. Amélia Regina Nogueira, o discente está matriculado na turma 11. A pesquisa encontra-se em andamento, na fase das discussões teórico-metodológicas, tem como objetivo geral: compreender o fenômeno da violência na cidade de Manaus a partir da percepção e da representação dos estudantes do ensino médio por meio dos mapas mentais. A etapa de aplicação da pesquisa de campo, será realizada com estudantes da $3^{\underline{a}}$ série do ensino médio da escola estadual Desembargador André Vidal de Araújo, situada na zona norte de Manaus.
\end{abstract}

Palavras-chave: Fenomenologia, Violência, Cidade.

\section{INTRODUÇÃO}

A violência praticada por indivíduos ou grupos, é um dos problemas mais recorrente e mais tratado, seja pela mídia como pelas instituições públicas e privadas. A criminalidade é um dos elos que formam ou alimentam o fenômeno da violência nas cidades, o morador vivencia esse fenômeno. Porém, os estudos ligados à violência dentro das cidades estão atrelados aos índices ou a busca de soluções que venham cessar ou minimizar principalmente as consequências desses atos, pouco se tem discutido a violência do ponto de vista de quem convive com essa situação, nesse caso o morador, pois este está diante dos atos violentos cotidianos da cidade. Portanto, como o estudante (morador) do ensino médio percebe e representa a violência que ele vivencia na zona norte da cidade de Manaus? A partir desse questionamento são propostos os seguintes objetivos para a pesquisa:

Objetivo Geral - Compreender o fenômeno da violência na cidade de Manaus a partir da percepção e da representação dos estudantes do ensino médio por meio dos mapas mentais.

Objetivos específicos: a) Discutir a violência urbana dentro da perspectiva fenomenológica, estabelecendo a percepção como categoria base na discussão;

REVISTA GEONORTE, V.9, N.33, p.256-259, 2018.

DOI: 10.21170/geonorte.2018.V.9.N.33.256.259

(ISSN 2237 - 1419) 
PERCEPÇÃO E REPRESENTAÇÃO DA VIOLÊNCIA: AS "PAISAGENS DO MEDO" NOS MAPAS MENTAIS DOS ESTUDANTES DO ENSINO MÉDIO NA ZONA NORTE DE MANAUS

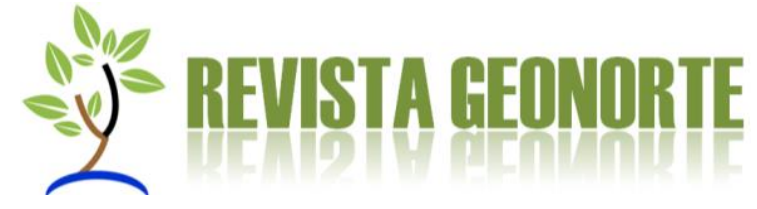

b) Identificar as "paisagens do medo" na zona norte de Manaus, percebidas e representadas pelos estudantes do ensino médio, estabelecendo os elementos que as formam;

c) Entender através dos mapas mentais como os estudantes do ensino médio percebem e representam a violência presente na paisagem.

O tema violência urbana é atual e como já afirmamos, é recorrente nos debates acadêmicos, na mídia e nas agências governamentais. $O$ debate acerca do conceito de violência também é abrangente e perpassa por diversos campos do conhecimento científico. Mas, não é um tema esgotado, ainda, há muito que se discutir sobre violência urbana, principalmente no tocante aos habitantes que vivem o cotidiano violento das cidades. Portanto não se trata de reformular teorias ou conceitos sobre o tema proposto, mas ampliar o debate para uma questão mais próxima de quem geralmente está exposto aos diversos atos violentos, tipificados como delituosos. O estudo está pautado não apenas no olhar do pesquisador, mas do pesquisado, essa é a questão relevante nessa pesquisa. $O$ estudo é voltado para quem vivencia a violência cotidiana, nesse caso específico o morador da cidade de Manaus.

\section{MATERIAIS E MÉTODOS}

O método de abordagem é o fenomenológico, segundo Dartigues (2008), este método renovou a maneira de abordagem dos fenômenos humanos. E, é dentro dessa perspectiva que esse trabalho se desenvolve.

A perspectiva fenomenológica permite segundo Merleau-Ponty (2011), o estudo das essências das coisas, e para entender tais essências, é preciso que haja a compreensão de quem as vivencia, o homem. Corroborando com essa afirmação, Nogueira (2014), enfatiza que dentro da fenomenologia, quem vive o fenômeno é extremamente importante: "A descrição aqui ressaltada não é apenas do sujeito que pesquisa, mas aquela de quem vive o fenômeno" (NOGUEIRA, 2014, p. 35). A escolha da fenomenologia como aposte teórico-metodológico nesse estudo, é a certeza de que os sujeitos envolvidos na pesquisa possam revelar novos elementos acerca do fenômeno estudado. A abordagem é qualitativa, com a formação de grupos focais e os instrumentos utilizados serão os mapas mentais produzidos pelos estudantes.

$\mathrm{Na}$ fase da pesquisa de campo, a mesma será aplicada aos estudantes da $3^{\underline{a}}$ série do ensino médio da escola estadual Desembargador André Vidal de Araújo, situada no bairro Cidade Nova, zona norte de Manaus. Os estudantes estão matriculados nas seis (6) turmas do turno matutino, serão selecionados 30 alunos dentre as turmas, a escolha da escola está relacionada ao fato de ser o ambiente de trabalho do mestrando, que atua como professor da mesma.

Os livros e os periódicos com as ideias de Yi-fu Tuan; Eric Dardel; Paul Claval; Merleau-Ponty; André Dartigues; Lívia de Oliveira e Amélia Nogueira, se apresentam como os principais materiais utilizados até esta etapa do trabalho. Nas etapas 
PERCEPÇÃO E REPRESENTAÇÃO DA VIOLÊNCIA: AS "PAISAGENS DO MEDO" NOS MAPAS MENTAIS DOS ESTUDANTES DO ENSINO MÉDIO NA ZONA NORTE DE MANAUS

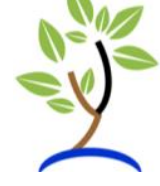

seguintes, os mapas mentais produzidos pelos estudantes, a caderneta de anotações, além das descrições dos evolvidos, também irão compor esse item.

\section{RESULTADOS E DISCUSSÃO}

Por se tratar de um projeto em andamento, os resultados e discussões ainda estão no campo dos debates teórico-metodológicos. As principais ideias trabalhadas até este estágio são: a Percepção como categoria primordial para esse trabalho e a Paisagem como categoria geográfica de análise.

Segundo Oliveira (2013), a Percepção está atrelada aos sentidos e torna-se uma linguagem, uma maneira de ver o mundo, é uma possibilidade de estender-se para o mundo, é um componente na leitura do ambiente em que se vive. Nogueira (2014) destaca que a categoria percepção utilizada hoje nos estudos geográficos advém das ideias de Marleau-Ponty, os estudos desse filósofo aproximaram os geógrafos da perspectiva fenomenológica.

Sobre Paisagem, Claval (2012) esclarece que esse termo não surge com os geógrafos, ele advém das artes, precisamente dos pintores, e referia-se a um quadro com moldura, que representava um pedaço da natureza, era como se o observador estivesse vendo através de uma janela. Segundo o autor, é a sistematização da geografia que fará com que os geógrafos se interessem pelo estudo da paisagem, ele ainda completa, destacando diversas linhas de pensamento pela qual a definição de paisagem perpassa na geografia, mas os novos caminhos que os estudos geográficos tomaram a partir da metade do século XX, levaram os geógrafos ao encontro da fenomenologia.

Seguindo a linha fenomenológica, temos a definição de Eric Dardel, baseada na vivência e na experiência, capazes de harmonizar a unidade visível: "Muito mais que uma justa posição de detalhes pitorescos, a paisagem é um conjunto, uma convergência, um momento vivido, uma ligação interna, uma 'impressão', que une todos os elementos". (DARDEL, 2011 p.30). Para o autor, a paisagem é concebida através da afetividade, uma espécie de ligação existencial com o lugar, embora, segundo ele a ciência tenha buscado definir a paisagem como algo externo ao homem.

A definição de Dardel é composta de subjetividade, assim a paisagem é concebida a partir dos sentidos, aspectos básicos da percepção, essa noção forma a base da definição de "Paisagem do Medo" de Yi-fu Tuan, pois está vinculado ao grau de afetividade que se constrói em relação aos lugares, nesse caso a percepção leva o sujeito a sentir-se bem ou ter medo do lugar onde vive, esse sentimento pode ter razões reais físicas materializadas, mas também podem ser invisíveis, apenas existentes na mente: "Paisagens do medo diz respeito tanto aos estados psicológicos como ao meio ambiente real." (TUAN, 2005 p.12). 
PERCEPÇÃO E REPRESENTAÇÃO DA VIOLÊNCIA: AS "PAISAGENS DO MEDO" NOS MAPAS MENTAIS DOS ESTUDANTES DO ENSINO MÉDIO NA ZONA NORTE DE MANAUS

\section{CONCLUSÕES}

Os estudos realizados até esta etapa nos cercam de certeza quanto ao caminho teórico-metodológico escolhido, as ideias discutidas por autores sobre as categorias que estão sendo analisadas e trabalhadas na pesquisa, revelam um novo arcabouço, que contribuem para o fortalecimento dos argumentos apresentados, assim como para o amadurecimento acadêmico do pesquisador. Certamente ainda temos muito que caminhar, porém, uma boa base teórica representa a possiblidade de êxito nas etapas seguintes.

\section{REFERÊNCIAS}

CLAVAL, P. A paisagem dos geógrafos. In: CORREA, Roberto Lobato; ZENY, Rosendahl. Geografia Cultural: uma antologia. Rio de Janeiro: EdUERJ, 2012 ( p. 245276)

DARDEL, E. O Homem e a Terra: a natureza da realidade geográfica. Trad. Werther Holzer. São Paulo: Perspectiva, 2011.

DARTIGUES, A. O que é Fenomenologia? Trad. Maria José J.G. Almeida. São Paulo: Centauro, 2008.

MERLEAU-PONTY, M. Fenomenologia da Percepção. Trad. Carlos Alberto Ribeiro de Moura. São Paulo: Martins Fontes, 2011.

NOGUERIA, A. R. B. Percepção e Representação Gráfica: A "Geograficidade" nos Mapas Mentais dos Comandantes de Embarcação no Amazonas. Manaus: Edua, 2014.

OLIVEIRA, L. Sentidos de Lugar e de Topofilia. Rio de Janeiro. Geograficidades. v.3 n.2 inferno p. 91-93, 2013. doc.pdf. Disponível em: www.uff.br/posarq/geograficidade/revista/index.php/geograficidade/issue/view/Invern 0\%202013\%3A\%20Dossiê\%20Geografia\%20e\%20Fenomenologia/showToc. Acesso em 10 de Dezembro de 2018.

TUAN, Y. Paisagens do Medo. Trad. Lívia de Oliveira. São Paulo: UNESP, 2005.

Recebido em 13/03/2018 Aceito em 30/05/2018 